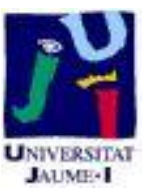

Título artículo / Títol article: Relationship between Young's modulus and temperature in porcelain tiles

Autores / Autors:

Antonio Pedro Novaes de Oliveira, Enrique Sanchez Vilches, Vicente Cantavella Soler, Francisco A. Gilabert Villegas

Revista:

Journal of the European Ceramic Society (2012), 32, 11

Versión / Versió:

Versión pre-print del autor

Cita bibliográfica / Cita bibliogràfica (ISO 690):
OLIVEIRA, Antonio Novaes de, et al. Relationship between Young's modulus and temperature in porcelain tiles. Journal of the European Ceramic Society, 2012, vol. 32, no. 11, p. 2853-2858

http://hdl.handle.net/10234/66035 


\title{
RELATIONSHIP BETWEEN YOUNG'S MODULUS AND TEMPERATURE IN PORCELAIN TILES
}

\author{
Antonio Pedro Novaes de Oliveira ${ }^{1}$, Enrique Sanchez Vilches ${ }^{2}$ \\ Vicente Cantavella Soler ${ }^{2}$, Francisco A. Gilabert Villegas ${ }^{2}$ \\ ${ }^{1}$ Department of Mechanical Engineering, Federal University of Santa Catarina, P.O. Box 476, \\ 88040-900, Florianópolis (SC), Brazil \\ ${ }^{2}$ Instituto de Tecnología Cerámica, Universitat Jaume I, Av. Vicent Sos Baynat s/n, 12006 \\ Castellon, Spain
}

\begin{abstract}
A focused research was conducted on samples prepared from an industrial porcelain tile composition containing quartz, used to produce ceramic floor tiles, with the aim of evaluating the variation of fired specimens' Young's modulus with temperature. These samples were fired in controlled laboratory conditions so that specimens with pre-existing cracks were obtained and subject to non-destructive in situ thermo-mechanical measurements (impulse excitation technique) in the $22-700^{\circ} \mathrm{C}$ temperature range during heating and cooling processes in order to find evidences to explain the hysteresis phenomenon in the Young's modulus versus temperature curve. The observed irreversible Young's modulus may be directly related to the pre-existent cracks that on heating and cooling are closed and opened up respectively, changing thus the Young's modulus which is well characterized by a hysteresis cycle.
\end{abstract}

Keywords: Fracture, Mechanical properties, Glass ceramics, Traditional ceramics

\section{Introduction}

Porcelain materials are produced mainly from natural raw materials such as clays, feldspar and quartz and/or alumina as reported in the literature [1-6]. Such materials show relatively good thermal, electrical, mechanical and chemical properties finding, for these reasons, applications in several sectors of society and industry including tableware [1-3], dental prosthesis [1], chemical ware [1], mechanical and structural items [1], low and high voltage electrical insulators [7-12] and ceramic tiles [1-3].

Although alumina and bauxite (aluminium hydroxide) porcelains are mechanically stronger [10], quartz porcelains are still produced since quartz is much cheaper than alumina [4-5]. Thus, in the fabrication of some porcelain parts such as electrical insulators and porcelain tiles, quartz is always the used filler raw material. However, because of the high coefficient of thermal expansion, $\alpha$ $\left(\alpha_{\text {quartz }}=12.3 \times 10^{-6}{ }^{\circ} \mathrm{C}^{-1}\right)[8,11]$ and structural transition of quartz ( $\alpha$-quartz at $573^{\circ} \mathrm{C}$ to $\beta$-quartz at $\left.574.3^{\circ} \mathrm{C}\right)[13,14]$ with volume variation $(0.68 \%)$ [13], most quartz porcelains show microcracks. The microcracks, in this case, are located in the interlayer (glassy phase) formed between the unsolved quartz particles and matrix and are originated by the resulting mechanical stresses as reported 
$[4,5,13-15]$. Fracture often occurs through the quartz particles $[5,13,16]$. Some microcracks have a circumferential orientation $[4,13,16]$ because in the cooling stage quartz contracts more than the glassy phase $\left(\alpha_{\text {glassy phase }}=3.0 \times 10^{-6}{ }^{\circ} \mathrm{C}^{-1}\right)[8,11]$. Consequently, the mechanical behavior of quartz porcelains may be unstable and not easily predictable.

To reduce the residual mechanical stresses in the produced quartz porcelains an optimized quartz particle size of $25 \mu \mathrm{m}$ should be used [4,5]. However, even using smaller quartz particles, microcracks may be still visualized by microscopy as reported in the literature [4,7-9]. Thus, microcracks are always present in quartz porcelain materials and the understanding of the crack formation and propagation mechanisms is important to know how to control or to avoid cracks in order to prolong the lifetime of quartz porcelain parts during service. Moreover, it is important to say that the microcracks, as reported above, were visualized after the materials were subjected to a single thermal cycle. Thus, by applying multiple thermal cycles the damage is expected to increase so that porcelains with lower mechanical strength are obtained and their lifetime shortened. In fact, according to our experiences, the damage seems to increase to some extent but almost stabilizes at the end of the thermal cycles. This partial conclusion is based on microscopy observations and in situ non-destructive thermo-mechanical tests relating the Young's modulus (E) with the temperature during heating and cooling processes. In this case, as reported in the literature [13] and according to the test method, a hysteresis in the Young's modulus versus temperature curve is observed. According to a previous research [13] the hysteresis observed in porcelain materials is attributed to microcracking on cooling and healing of the microcracks during heating, in the region around the $\alpha-\beta$ quartz transition. Moreover, as set out elsewhere [17-18], porosity and metakaolinite transformation in the $429-740^{\circ} \mathrm{C}$ temperature range, in the early firing stage, negatively affect the Young's modulus behavior. On the other hand, as reported [4] cristobalite formation on cooling in the $225-250^{\circ} \mathrm{C}$ temperature range and residual mullite may act as a microstructural reinforcing and so improving the mechanical strength of quartz porcelains. In this case cristobalite, according to a previous research [4], forms from unsolved quartz particles and/or from the supersaturated glassy phase by devitrification. However, as set out by Libermann $[8,9]$, cristobalite and quartz play a deleterious role and must be avoided in porcelains for production of high voltage electrical insulators. Even so, although many efforts have been done to explain the hysteresis phenomenon in quartz porcelains, no clear evidences were found in the literature. A clear understanding of the hysteresis phenomenon may be the key to design porcelain materials with better performance and reliability for a specific application.

In this context, a focused research was conducted on samples prepared from an industrial porcelain tile composition containing quartz (used to produce ceramic floor tiles). These samples were fired in controlled laboratory conditions so that specimens with pre-existing cracks, observed by SEM, were obtained and subject to non-destructive in situ thermo-mechanical measurements (impulse excitation technique) in the $22-700^{\circ} \mathrm{C}$ temperature range during heating and cooling 
processes in order to find evidences to explain the hysteresis phenomenon in the Young's modulus versus temperature curve.

\section{Materials and methods}

An industrial spray-dried porcelain tile powder (5.5 wt.\% humidity) used in the production of singlefired floor tiles was chosen. The powder was prepared in an industrial plant by wet grinding in a continuous ball mill. The slurry obtained was sieved (residue below $1 \mathrm{wt}$. \% on a $40 \mu \mathrm{m}$ mesh). This particle distribution is of fundamental importance in increasing the green tile density and consequently in improving the reactivity of particles to obtain finished porcelain stoneware tiles with appropriated mechanical properties and good textural characteristics.

The resulting deflocculated, concentrated aqueous suspension was spray dried. This represents the normal practice followed in ceramic factories for the preparation of tile ceramic bodies.

To characterize the ceramic body and fired ceramic samples, X-ray diffraction and chemical analysis were performed. The chemical analysis of the ceramic body was conducted by the X-ray fluorescence spectroscopy technique (PANalytical model Axios, Netherlands) after the samples were mineralized in a concentrated $\mathrm{HF} / \mathrm{HCl} 1: 1$ solution. X-ray diffraction was performed by a powder XRD (Broker AXS D8 diffractometer, Germany) diffractometer using Ni-filtered CuK $\alpha$ radiation in the $10-70^{\circ} 2 \theta$ angle range. The crystalline phases were indentified from peak position and relative intensity, using reference data from the JCPDS Handbook. The quartz fraction was determined with the Rietveld method [22], using $\mathrm{CaF}_{2}$ as internal standard.

With the aim of verifying the influence of the temperature on the Young's modulus (E) the spraydried powders (moisture content of $5.5 \mathrm{wt}$ \% on a dry basis) were uniaxially pressed at $45 \mathrm{MPa}$ by means of an automatic hydraulic press so that samples with nominal dimensions of $80 \mathrm{~mm} \times 20$ $\mathrm{mm} \times 7 \mathrm{~mm}$ were obtained. Subsequently, the compacted samples were dried in a muffle oven at $110^{\circ} \mathrm{C}$ for $2 \mathrm{~h}$ and then fired in an electric furnace (Pirometrol $\mathrm{R}$, Spain) at a heating rate of $70^{\circ} \mathrm{C} / \mathrm{min}$ between 25 and $500^{\circ} \mathrm{C}$, and $25^{\circ} \mathrm{C} / \mathrm{min}$ from $500^{\circ} \mathrm{C}$ to the maximum firing temperature $\left(1210^{\circ} \mathrm{C}\right)$. The holding time at the firing temperature was $6 \mathrm{~min}$, followed by different cooling rates (slow cooling: natural cooling inside the furnace and fast cooling: air flow, 1 bar pressure) so that the average measured water absorption (UNE EN ISO 10545-3: 1997) in the fired bodies was lower than $0.5 \%$.

Non-destructive in situ thermo-mechanical measurements, based on the impulse excitation technique (Grindosonic, Belgium), were performed in the $22-700^{\circ} \mathrm{C}$ temperature range in order to determine Young's modulus versus temperature during heating and cooling of the samples. In this case, the samples were heated at a rate of $6.5^{\circ} \mathrm{C} / \mathrm{min}$ and 3 thermal cycles of heating and cooling were registered. 
To visualize microcracking in the samples after firing process, scanning electron microscopy (Philips XL30 CP) was used.

\section{Results and Discussion}

\subsection{Ceramic body characterization}

Chemical and mineralogical analyses (Table 1 and Figure 1) of the used ceramic body indicate the presence of clay minerals (kaolinite and illite / muscovite), sodium feldspars. The calculated amount of quartz by the Rietveld method was $20 \mathrm{wt} . \%$. Due to this particular chemical and mineralogical composition, the mechanical properties of the ceramic body after firing and its near zero water absorption are assured through the formation of new compounds, such as mullite and glassy phase as shown in Figure 2 for a fired ceramic sample. These new crystalline phases are the result of the reaction between the alkaline oxides from feldspars and amorphous dehydroxylation products of the clay minerals and free quartz as reported elsewhere [23].

\subsection{Microstructure and thermal mechanical behavior}

Figure 3 shows SEM micrographs related to slow and fast cooled fired samples. As it can be seen from Figure 3, samples in both conditions of cooling show microcracks around the quartz particles. These microcracks are very common in porcelain materials and they contribute to the failures verified in the components during service. At higher magnifications (Figures $3(b)$ and (d)) it is possible to see microcracks located in the interlayer formed between the unsolved quartz particles and matrix, and also through the quartz particles as reported in the literature [19]. The microcracks display very frequently a circumferential orientation because in the cooling stage quartz shrinks more than the glassy phase. Consequently, the mechanical behavior of quartz porcelains may be unstable and not easily predictable. In fact, according to Figure 4, which shows curves representing the Young's modulus as a function of the temperature $\left(22-700^{\circ} \mathrm{C}\right)$ for 3 thermal cycles of heating and cooling (same heating and cooling rates), the mechanical behavior of the precracked samples is not reversible. Figure 5 shows the hysteresis (Young's modulus difference between cooling and heating) for the specimens under fast and slow coolings. As can be observed, cooling rate does not have a significant impact on the hysteresis. This result agrees with the fact that no big differences have been found on the microstructure (Figure 3).

As the temperature increases, the Young's modulus decreases almost linearly up to the quartz transition at $573^{\circ} \mathrm{C}$. Then the Young's modulus strongly increases up to the test temperature $\left(700^{\circ} \mathrm{C}\right)$. The decrease of the Young's modulus as the temperature increases was expected at least if no phase transformation, i.e., no structural changes occur. If a structural change occurs, as in the case of pure quartz [14], the Young's modulus increase due to this transformation is also observed in the samples. In fact, according to Ault and Ueltz [20], quartz inversion can also be 
detected even though only very small amounts of free quartz are present; for example, the inversion was clearly observed in a body containing only about $2 \%$ free quartz.

However, during the heating cycle a hysteresis in the samples is observed and it is accentuated for temperatures lower and around the quartz transition. It is possible to observe that on heating the samples up to about the quartz transition temperature the Young's modulus is almost the same after 3 thermal cycles but it is a little higher after the second and third thermal cycles for temperatures higher than $600^{\circ} \mathrm{C}$. On cooling down the samples the Young's modulus follows almost the same curve for each applied thermal cycle but decreases a little from the first to the third thermal cycles from about 550 to $200^{\circ} \mathrm{C}$.

Based both in these evidences as in information reported in literature, it can be assumed that from temperatures above quartz transition the glassy matrix is still able to accommodate certain level of thermo-mechanical stresses. It is reasonable to think that viscous flow is present [21], thus some "necks", or solid bonds, are expected to form. This may explain why the Young's modulus increases on cooling after the second and third thermal cycles. As the temperature decreases, the coefficient of thermal expansion of quartz strongly increases up to the quartz transition temperature; however, since the viscous flow is still present, the mechanical stresses can be compensated (relieving of stresses). Once the temperature decreases below the quartz transition, the coefficient of thermal expansion of quartz increases faster than of the matrix. Therefore, the quartz particles start to shrink and generate stresses. Even so, particularly within the temperature range $550-200^{\circ} \mathrm{C}$, the Young's modulus is higher than that on heating, and it decreases a little after second and third thermal cycle. Nevertheless, its behavior tends to become more stable. The increase of the Young's modulus on cooling may be related to the neck formations between the cracks interfaces, which require additional energy to break the solid bonds (Figure 6). In fact, the almost constant Young's modulus of the specimen within the range $550-200^{\circ} \mathrm{C}$ may be explained by the compensation of two effects: the break of solid bonds and the increase in quartz Young's modulus when the temperature decreases.

Assuming a mixture law, it is possible to calculate Young's modulus evolution if no cracks were present: $E=V_{m} E_{m}+V_{q} E_{q}$, where $V_{i}$ is the volume fractions ( $i=m$ : matrix; $i=q$ : quartz), and $E_{i}$ is the Young's modulus of the $\mathrm{i}$-phase. If $E_{m}$ does not change with temperature, the variation of Young's modulus can be calculated as: $\Delta E=V_{q} \Delta E_{q}$. The advantage of the latter expression is that $\square E$ is not a function of $E_{m}$. Results of this equation are shown in Figure 7. Below $550 \stackrel{\circ}{\mathrm{C}}$, Young's modulus calculated theoretically is high; and the difference may be due to cracks.

On this basis it is possible to say that the observed hysteresis may be directly related to the preexistent cracks that on heating and cooling are closed and opened up respectively, thus changing the Young's modulus. 


\section{Conclusions}

Porcelain tile ceramic samples were prepared and obtained by usual industrial and laboratory techniques. Samples after firing process showed typical glassy and crystalline phases and cracks around the quartz particles as well as pores, which were detected and observed by XRD and SEM analyses.

On heating and cooling pre-cracked samples, the Young's modulus was not reversible, i.e., hysteresis took place. As the temperature increased the Young's modulus decreased almost linearly up to the quartz transition at $573^{\circ} \mathrm{C}$, when the Young's modulus strongly increased up to the tested temperature $\left(700^{\circ} \mathrm{C}\right)$. This Young's modulus increasing was attributed to the quartz inversion, since it happens above the quartz transition temperature $\left(573^{\circ} \mathrm{C}\right)$ as reported in the literature, and to the closing of the pre-existents cracks.

On cooling, in particular for temperature below the quartz transition temperature, the Young's modulus increased since an additional energy was necessary to break the solid bonds originated at high temperatures.

The almost constant Young's modulus in the $550-200^{\circ} \mathrm{C}$ temperature range may be explained by the compensation between the break of the solid bonds (necks) and the increase in quartz Young's modulus.

The results of this work contribute to a better understanding of quartz behavior in porcelain ceramics. The analysis of the hysteresis curves can be used as an interesting complementary method to determine the influence of other variables such as particle size distribution, mass fraction and composition of crystalline particles, etc. This will be helpful to produce more suitable porcelain tiles for specific applications.

\section{Acknowledgments}

The authors are thankful for the financial support provided by the project CAPES MECD-DGU $321 / 2010$ between Brazil and Spain and by the Ministry of Science and Innovation, within the National Programme for Fundamental Research Projects (BIA2009-10692).

\section{References}

[1] Haber RA, Smith PA. Overview of Traditional Ceramics. In: Ceramics and Glasses, Metals Park: ASM International; 1991, p. 3-6. 
[2] Wood RK. Ceramic whiteware. In: Ceramics and Glasses, Metals Park: ASM International; 1991, p. $930-936$

[3] Manfredini T, Pellacani GC. Tile whiteware. In: Ceramics and Glasses, Metals Park: ASM International; 1991, p. 925-929.

[4] Carty WM, Senaparti U. Porcelain raw materials: Processing, phase evolution and mechanical behavior. J Am Ceram Soc 1998; 81: 38-43.

[5] Chinelatto AL, Souza DPF de. Porcelanas elétricas aluminosas: Parte I - Revisão da literatura. Cerâmica 2004; 50: 62-68.

[6] Sanchez Vilches E, Orts MJ, Garcia-Ten J, Cantavella Soler, V. Porcelain tile composition effect on phase formation and products, Am Ceram Soc Bull 2001; 80: 43-49.

[7] Liebermann J. Reliability of materials for high-voltage insulators. Am Ceram Soc Bull 2000; 80: 55-58.

[8] Liebermann J. Avoiding quartz in alumina porcelain for high-voltage insulators, Part 1. Am Ceram Soc Bull 2001; 80: 37-42.

[9] Liebermann J. Avoiding quartz in alumina porcelain for high-voltage insulators, Part 2. Am Ceram Soc Bull 2001; 80: 43-48.

[10] Liebermann J, Schulle W. Bauxite porcelain: A new high-tech product for high-voltage insulation. Am Ceram Soc Bull 2002; 81: 33-38.

[11] Liebermann J. Microstructure properties and product quality of strength-stressed high-voltage insulators. Am Ceram Soc Bull 2003; 82: 39-46.

[12] Bonetti A, Tomelin JC, Alarcon OE, Oliveira APN, Hotza D. Desenvolvimento de porcelana quartzosa para isoladores elétricos de alta tensão. Exacta 2009; 7: 187-194.

[13] Stubna I, Trník A, Vozár L. Thermomechanical analysis of quartz porcelain in temperature cycles. Ceram Int 2007; 33: 1287-1291.

[14] Ohno I, Harada K, Yoshitomi C. Temperature variation of elastic constants of quartz across the $\alpha-\beta$ transition, Phys Chem Miner 2006; 33: 1-9.

[15] Noni A de, Hotza D, Cantavella Soler V, Sanchez Vilches E. Influence of composition on mechanical behaviour of porcelain tile. Part II: Mechanical properties and microscopic residual stress. Mater. Sci. Eng. A, 2010; 527: 1736-1746.

[16] Ohya Y, Takahashi Y. Acoustic emission from a porcelain body during cooling. J Am Ceram Soc 1999; 82: 445-448.

[17] Stubna I, Trník A. Young's modulus of porcelain mixture after firing in the dehydroxylation region. Ceramics-Silikáty 2007; 51: 102-105. 
[18] Kilikoglou V, Vekinis G, Maniatis Y, Day PM. Mechanical performance of quartz-tempered ceramics: Part I, Strength and toughness. Archaeornetry 1998; 40: 261-279.

[19] Noni Junior A de, Hotza D, Cantavella Soler V, Sánchez Vilches E. Effect of quartz particle size on the mechanical behaviour of porcelain tile subjected to different cooling rates. $J$ Eur Ceram Soc 2009; 29: 1039-1046

[20] Ault NN, Ueltz HFG. Sonic analysis for solid bodies. J Am Ceram Soc 1953; 36: 199-203.

[21] Lachman IM, Everhart JO. Development of safe cooling schedules for structural clay products. J Am Ceram Soc 1956; 39: 30-38.

[22] Young RA. The Rietveld Method. Oxford: University Press; 1996.

[23] Sánchez E, García-Ten J, Sanz V, Moreno A. Porcelain tile: almost 30 years of steady scientific-technological evolution. Ceram Int 2010; 36: 831-845. 


\section{FIGURES AND TABLES CAPTIONS}

\begin{tabular}{|c|c|}
\hline Table 1. & Chemical analysis of the tested porcelain tile body. \\
\hline Figure 1. & $\begin{array}{l}\text { X-ray diffraction of the porcelain tile body. Q: quartz, FNa: sodium feldspar, K: } \\
\text { kaolinite, I/M: illite/muscovite }\end{array}$ \\
\hline Figure 2. & $\begin{array}{l}\text { X-ray diffraction of the porcelain tile body fired at } 1210^{\circ} \mathrm{C} \text { for } 6 \text { min. Q. quartz, } \\
\text { FNa: sodium feldspar, Mu: mullite }\end{array}$ \\
\hline Figure 3. & $\begin{array}{l}\text { SEM micrographs of porcelain tile body samples fired at } 1210^{\circ} \mathrm{C} \text { for } 6 \text { min. (a), (b) } \\
\text { slow cooled samples; (c), (d) fast cooled samples. (Slow cooling: natural cooling } \\
\text { inside the furnace and fast cooling: air flow, } 1 \text { bar pressure). }\end{array}$ \\
\hline Figure 4. & $\begin{array}{l}\text { Young's modulus vs. temperature of pre-cracked samples of the tested porcelain } \\
\text { tile body (fast cooling). }\end{array}$ \\
\hline Figure 5. & Hysteresis during the 3rd cycle of samples after fast and slow cooling. \\
\hline Figure 6. & Proposed mechanism to explain thermal hysteresis \\
\hline Figure 7. & $\begin{array}{l}\text { Theoretical evolution of Young's modulus assuming a simple mixture law. } \\
\text { Comparison with experimental results. }\end{array}$ \\
\hline
\end{tabular}


Table 1.

\begin{tabular}{|l|l|}
\hline Oxyde & $\%$ wt \\
\hline $\mathrm{SiO}_{2}$ & 68.2 \\
$\mathrm{Al}_{2} \mathrm{O}_{3}$ & 19.1 \\
$\mathrm{Fe}_{2} \mathrm{O}_{3}$ & 0.63 \\
$\mathrm{CaO}$ & 0.74 \\
$\mathrm{MgO}$ & 0.63 \\
$\mathrm{Na}_{2} \mathrm{O}$ & 4.26 \\
$\mathrm{~K}_{2} \mathrm{O}$ & 1.36 \\
$\mathrm{TiO}_{2}$ & 0.63 \\
$\mathrm{MnO}$ & $<0.01$ \\
$\mathrm{P}_{2} \mathrm{O}_{5}$ & 0.09 \\
$\mathrm{ZnO}_{\mathrm{ZnO}}$ & 0.04 \\
$\mathrm{ZrO}$ & 0.08 \\
loss on ignition & 3.99 \\
\hline
\end{tabular}


Figure 1.

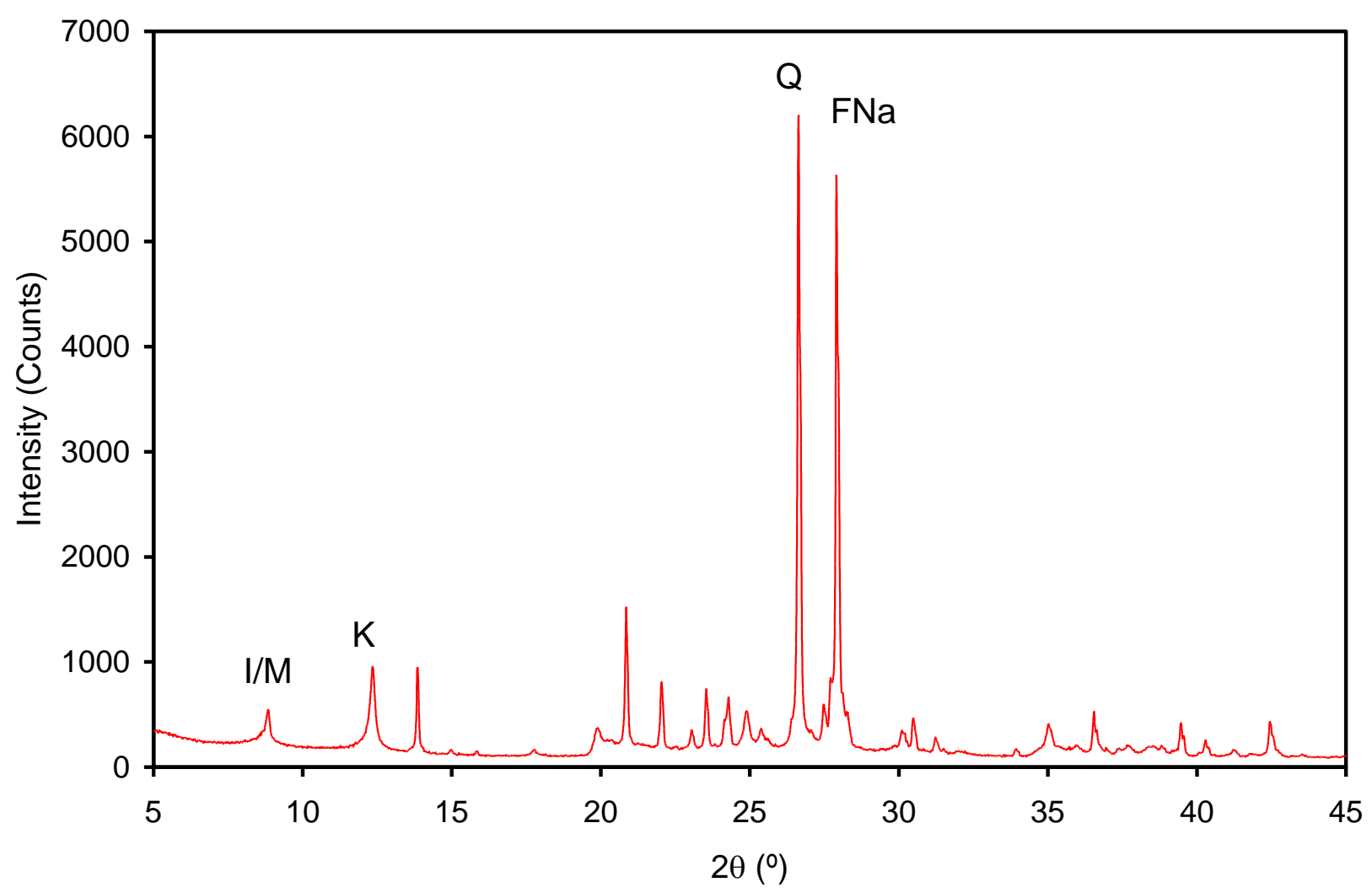

Figure 2.

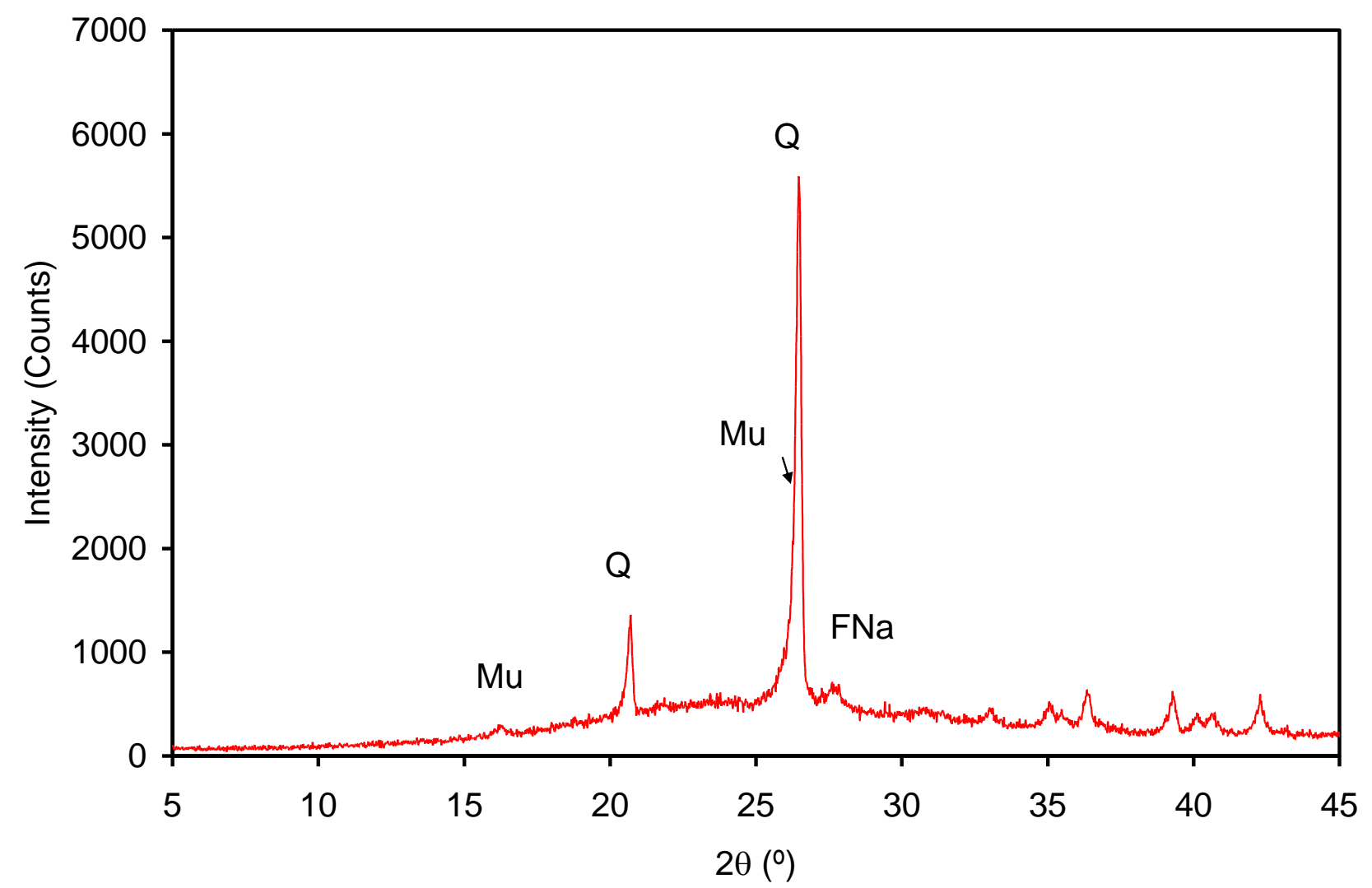


Figure 3.




Figure 4.

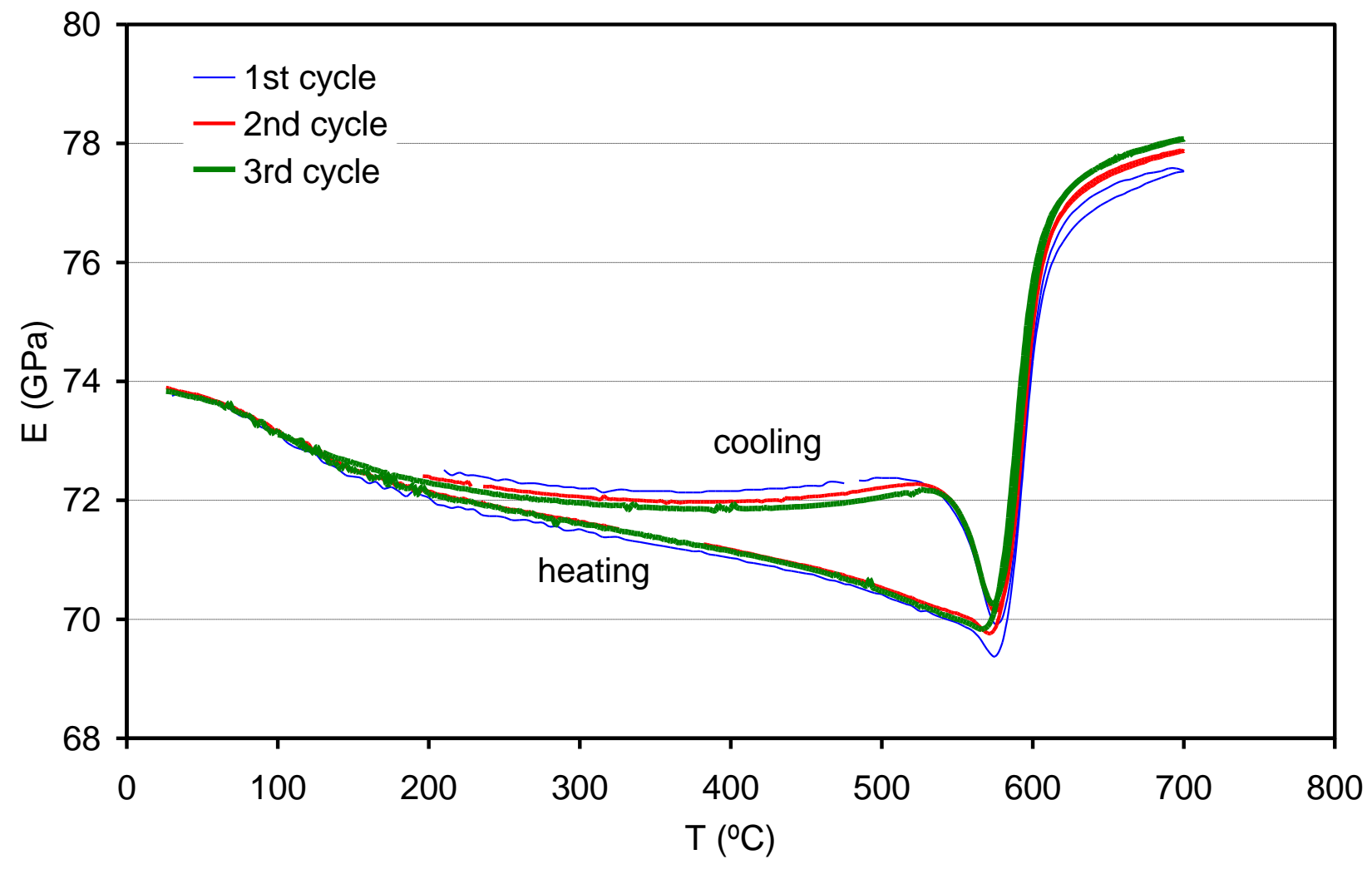

Figure 5.

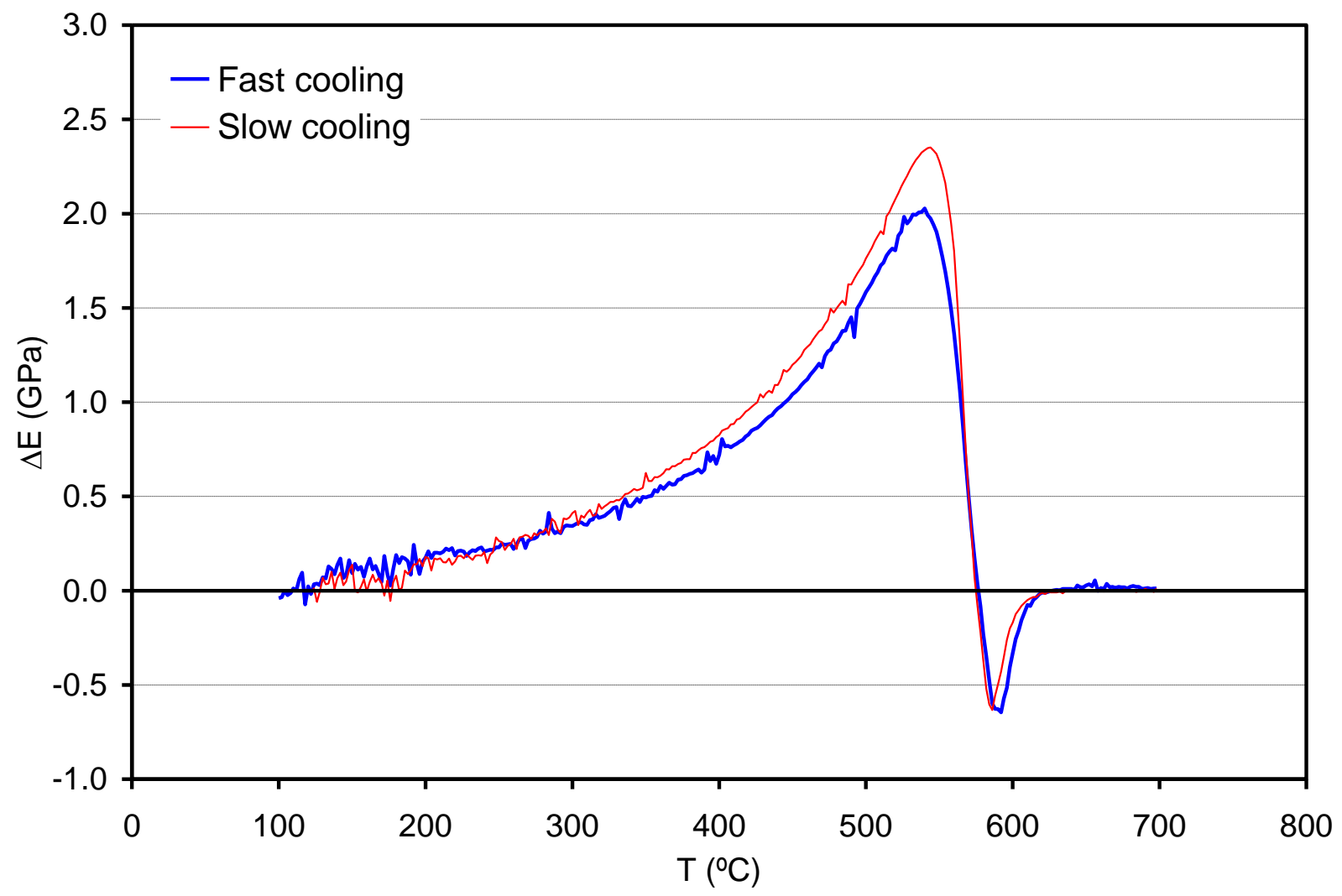


Figure 6.
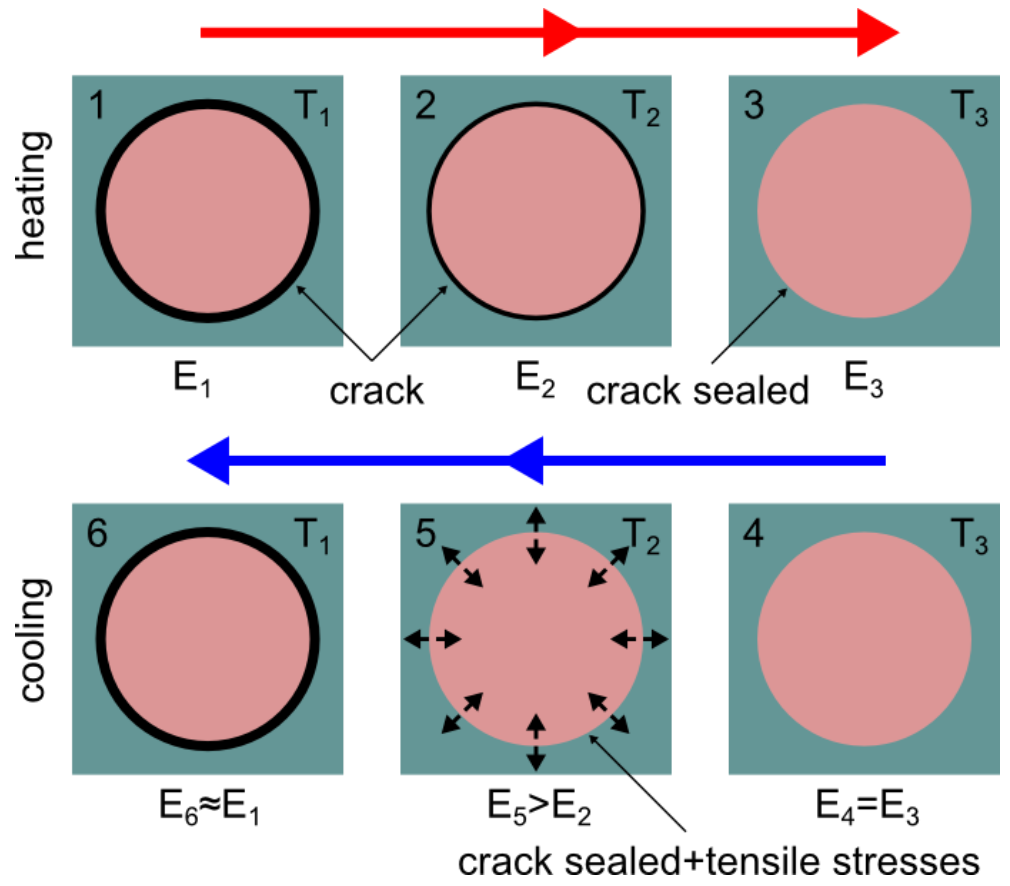

Figure 7.

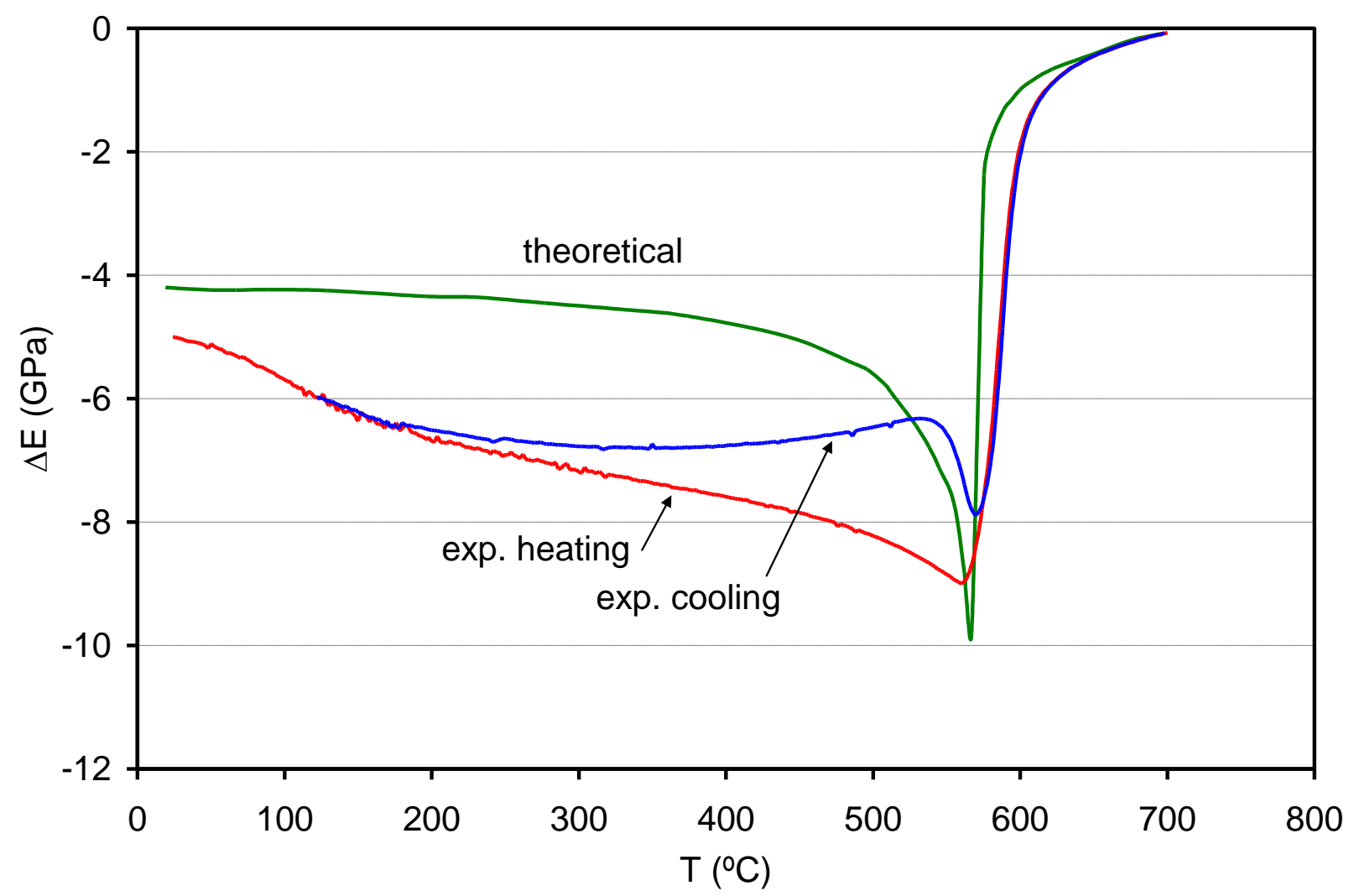

